\title{
GPS-analyse afjordskaelvet - flyttede Sumatra sig virkelig 36 meter?
}

Af Ólafur Gudmundsson, Niels Bohr Institutet, Københavns Universitet og Shfaqat Abbas Khan, Danmarks Rumcenter

Anden juledag 2004 blev Sydøstasien rystet af et kraftigt jordskælv, der målte $M_{w}=9,3$ på Richterskalaen. Jordskælvet er det næstkraftigste registreret siden 1900. Jordskælvet fandt sted ca. $100 \mathrm{~km}$ vest for det nordlige Sumatra, hvor den relativt tynde Indo-Australske lithosfæreplade bevæger sig ind under den noget tykkere Burmesiske plade.

I gennemsnit bevæger den Indo-Australske plade sig ca. $6 \mathrm{~cm} /$ år mod den Burmesiske plade, men ved jordskælvet d. 26. december rykkede begge plader flere meter mod hinden på ganske kort tid. Resultatet var voldsomme flodbølger på flere meters højde, som med deres enorme styrke ødelagde kysterne langs Indonesien, Sri Lanka, Indien, Malaysia, Somalia samt andre lande og krævede mere end 290.000 menneskeliv.

Flyttede Sumatra sig virkelig 36 meter For et jordskælv med sådan en styrke, må forventes bevægelser af overflade omkring sprækkezonen i størrelsesorden af flere meter. Ifølge massemedierne flyttede Sumatra sig 36 meter og de mindre øer vest for Sumatra op til 20 meter. Men hvad var de faktiske deformationer omkring Sumatra? Kan det passe at Sumatra flyttede sig 36 meter? Hvor store var overfladebevægelserne som genererede flodbølgerne? Eller rettere, hvad var deformationerne omkring sprækkezonen? Svaret kan findes dels ved at analysere amplituder af de seismiske bølger fra jordskælvet observeret med seismogrammer verden over, dels ved direkte måling af jordskorpens bevægelse ved hjælp af det globale positioneringssystem, GPS, eller ved simpel modellering af forkastningen omkring jordskælvet.

\section{GPS-observationer}

GPS er et satellitbaseret positioneringssystem. Ud fra kendskab til GPS-satellitternes præcise position er det muligt at bestemme de geografiske koordinater for et vilkårligt punkt på jordoverfladen. Der er

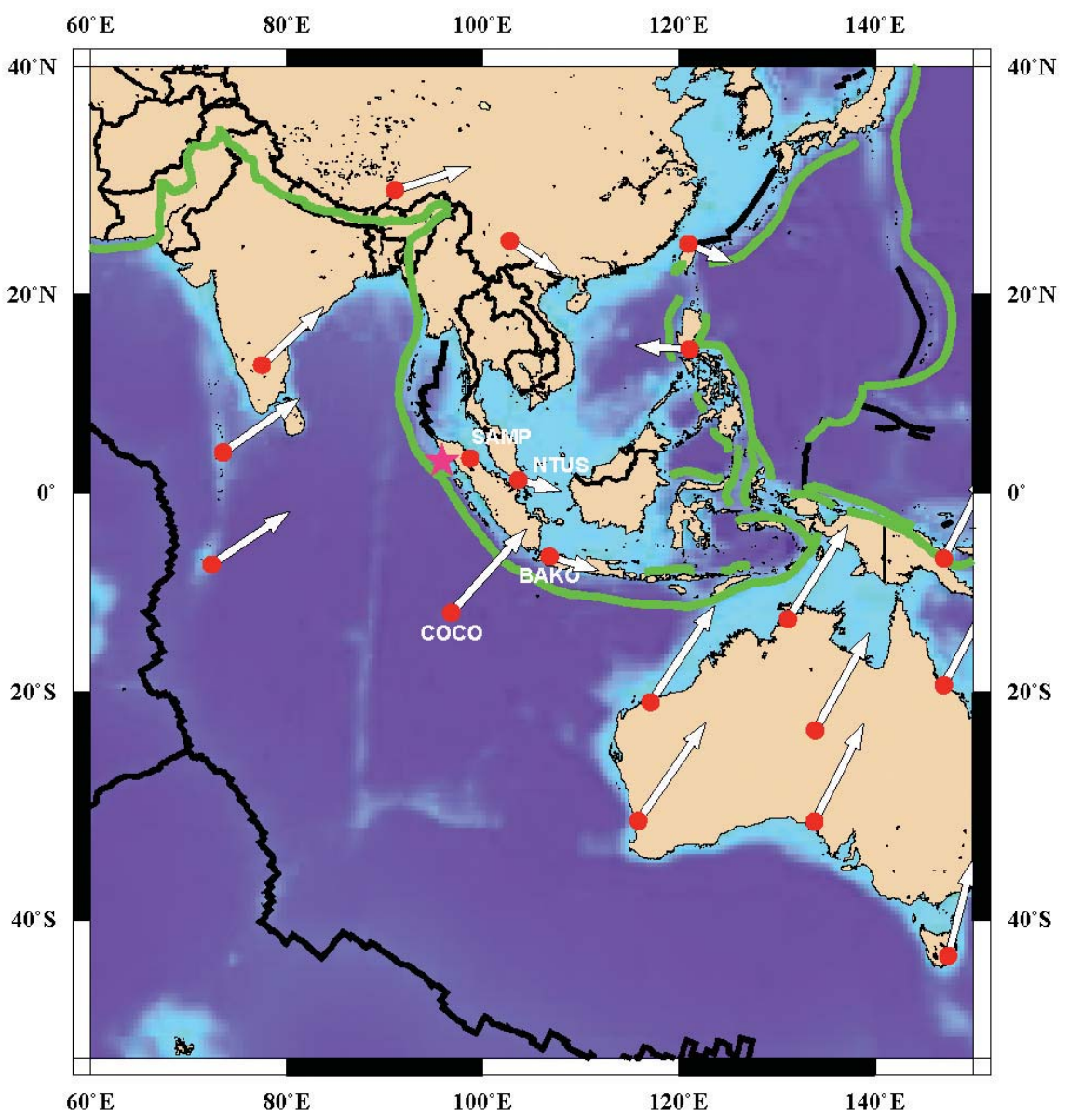

GPS stationernes horisontale bevagelse. De tykke sorte og grønne linere angiver pladegrcenser. Den røde stjerne i midten af figuren angiver epicentret for det store jordskcelv 26/12-2004. (Grafik: Forfatterne)

konstant minimum 24 GPS-satellitter i kredsløb om Jorden, hvilket gør det muligt at bestemme koordinater for et punkt på jordoverfladen med få centimeters nøjagtighed, når man midler over 24 timer. GPS er således et velegnet redskab til analyse af deformationsmønsteret omkring et kraftigt jordskælv som det ved Sumatra.

De røde prikker i figuren ovenfor viser GPS stationer i Sydøstasien. Stationerne har været aktive i flere år og dermed gjort det muligt at bestemme bevægelses hastighed og retning for såvel den Indo-Australske plade som den Burmesiske plade. Pilene i figuren angiver i hvilken retning, GPS-stationerne bevæger sig, og størrelsen af pilene angiver hastigheden. For at undersøge deformationer af jordoverfladen forårsaget af jordskælvet 26. december er de fire GPS-stationer benyttet, som ligger tættest jordskælvets epicenter. Stationen NTUS (Nanyang Technological University) ligger i Singapore, og stationerne BAKO (Bakosurtanal) og SAMP (Sampali) ligger i Indonesien. Station, COCO, ligger på Cocos Øerne.

Figuren på næste side viser ændringer $\mathrm{i}$ positionen for SAMP. Figur a viser ændringer i den nordlig retning, figur $b$ den vestlige retning, og figur c viser den vertikale ændring (positiv opad). De horisontale ændringer som vist på figuren er midlet over 5 dage, hvorimod de vertikale ændringer er midlet over 15 dage. Den røde linie viser et "offset" plus en lineær variation estimeret til koordinaterne. Offsettet er indført ved datoen 26/12-2004 og angiver således et udtryk for, hvor meget stationen har flyttet sig som følge af jordskælvet. Forskydninger i den nordlige, østlige og vertikale retning for SAMP er hhv. $-12,0 \pm 1,9 \mathrm{~mm},-142,3 \pm 3,3$ 

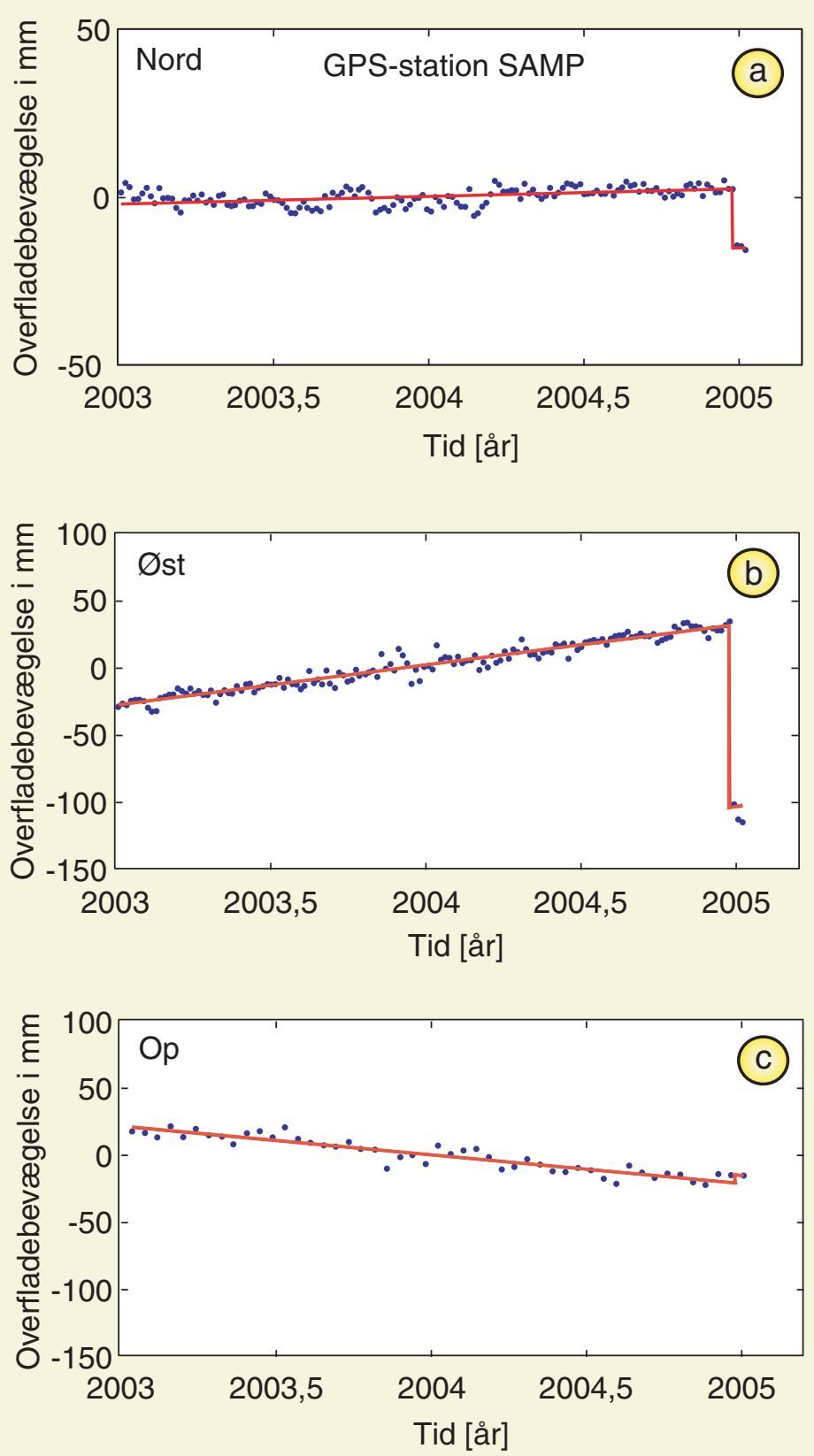

Endringer i positionen for SAMP. Figur a viser cendringer $i$ den nordlig retning, figur $b$ den vestlige retning og figur c viser vertikale andring (positiv opad). De horisontale andringer som vist på figuren er midlet over 5 dage, hvorimod de vertikale cendringer er midlet over 15 dage. Den røde linie viser et "offset" plus en linear variation estimeret til koordinaterne. Offsettet er indført ved 26/122004. Den linecere variation $i$ hhv. nordlig og østlig retning skyldes pladebevagelsen. (Grafik: Forfatterne)

$\mathrm{mm}$ og $6,7 \pm 7,8 \mathrm{~mm}$. SAMP er dermed rykket mod vest (V5S) under jordskælvet. Tilsvarende er forskydningerne i den nordlige, østlige og vertikale retning for stationen NTUS hhv. $6,0 \pm 1,7 \mathrm{~mm},-19,7 \pm 2,2 \mathrm{~mm}$ og $1,8 \pm 7,5 \mathrm{~mm}$. NTUS er rykket mod vest (V17N) under jordskælvet. Stationerne COCO og BAKO har ikke vist nogen målbar flytning i hverken den nordlige, østlige eller vertikale retning.

\section{Forkastningsmodel}

Ved hjælp af simple antagelser er det muligt at beskrive deformationsmønsteret omkring forkastningen. Det antages, at forkastningen er vinkelret og i et elastisk halvrum med jævn bevægelse over hele forkastningen. Dernæst skal forkastningens geometri antages dvs. forkastningens længe, bredde samt orientering.

Denne kan estimeres ud fra jordskælvets styrke og efterskælvaktiviteten. Jordskælvets styrke som er $\mathrm{M}_{\mathrm{w}}=9,3$ giver et seismiske moment på $\left(\mathrm{M}_{\mathrm{o}}=1,3 \times 10^{23} \mathrm{Nm}\right)$ og efterskælvaktiviteten anslår en forkastningslængde på ca. $1.200 \mathrm{~km}$ som vist på figuren på næste side. For bedst muligt at beskrive geometrien er forkastningen delt op i 4 sek-

\section{Geologisk Tidsskala}

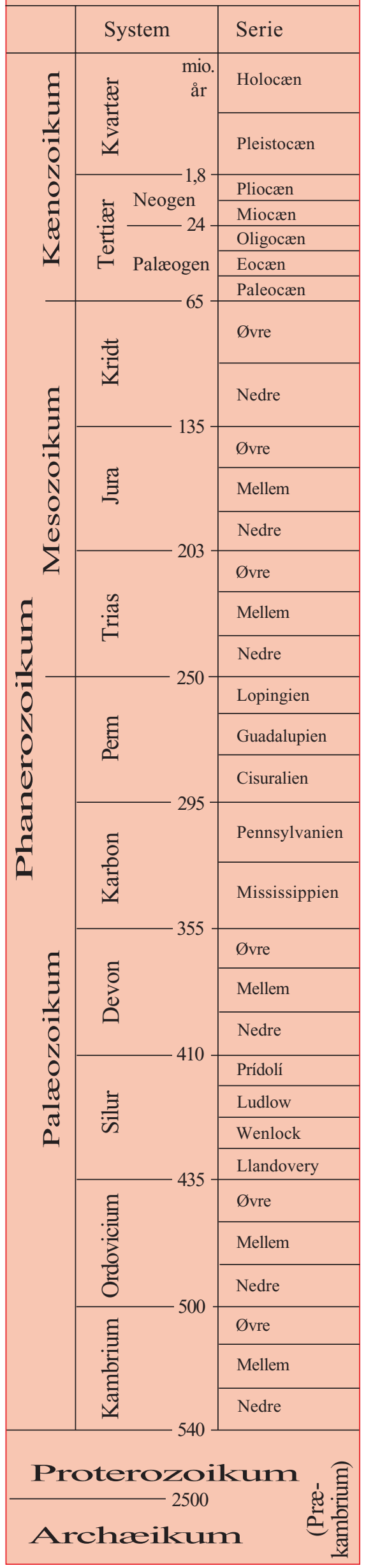




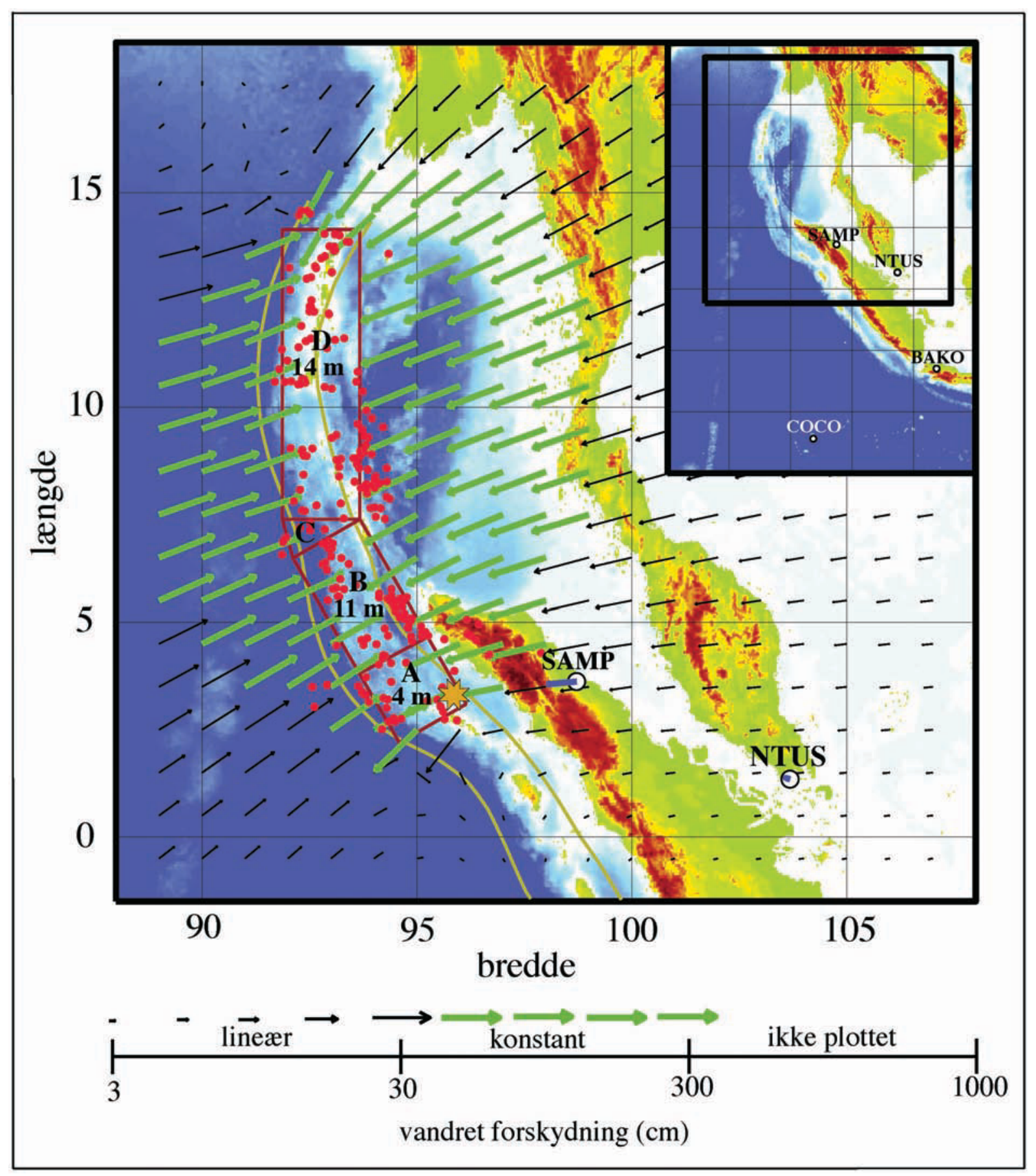

Kort over regionen omkring Sumatra-Andaman-jordskcelvet. Epicentret for Sumatra-Andaman-jordskcelvet er angivet med en gul stjerne. De røde cirkler reprasenterer efterskcelvene frem til 20. januar 2005 (data er hentet fra NIEC). GPS-stationerne SAMP og NTUS er angivet med hvide cirkler. BenioffWsadati zone for dybderne $0 \mathrm{~km}$ og $50 \mathrm{~km}$ er angivet som gule kurver. De røde kasser reprcesenterer forkastningsgeometrien. De blå pile ved hhv. SAMP og NTUS reprcesenterer observerede overfladeflytninger. De sorte og grønne pile reprcesenterer bevagelser baseret på forkastningsmodellen. (Grafik: Forfatterne)

tioner A, B, C og D. De gennemsnitlige deformationer i hver sektion er angivet i figuren til højre. Den gennemsnitlige bevægelse er ca. 4 meter i sektion A, ca. 11 meter i sektion B og ca. 14 meter i sektion D. De relative små bevægelser i sektion A skyldes justering til GPS observationer.

De horisontale bevægelser af jordoverfladen beregnet udfra ovennævnte model er angivet med sorte og grønne pile i figuren til højre. De sorte pile repræsenterer bevægelser op til $30 \mathrm{~cm}$, og de grønne pile repræsenterer bevægelser mellem $30 \mathrm{~cm}$ og $300 \mathrm{~cm}$. Herudover er vist blå pile i figuren, som angiver bevægelser observeret med GPS. Be- vægelser større end 1 meter er ikke anført, da det blot vil gøre figuren uoverskuelig.

\section{Konklusion}

GPS-stationerne COCO og BAKO ligger i en afstand af hhv. ca. 1.700 kilometer og 1.600 kilometer syd for epicentret og viser ingen målbare deformationer. Dette er i overensstemmelse med efterskælvsaktiviteten, som også viser, at forkastningens sydlige ende ligger omkring det store skælv. De målte bevægelser ved SAMP og NTUS er også i overensstemmelse med modellen både i størrelse og retning.

Det bør bemærkes, at GPS-målinger ude- lukkende giver et overblik over deformationsmønsteret omkring forkastningens sydlige ende. Det er derfor ikke muligt udfra GPS-observationerne at sige noget om størrelsen af forskydningerne ved forkastningens nordlige ende. Ud fra GPS-observationerne og den simple modellering af forkastningen kan med sikkerhed siges, at Sumatra ikke har flyttet sig $36 \mathrm{~m}$ som omtalt i pressen. De horisontale forskydninger omkring Sumatras nordøstlige del er ca. $10 \mathrm{~cm}$, hvorimod den nordvestlige del i gennemsnit har flyttet sig ca. $80 \mathrm{~cm}$ til få meter. Den mellemste og sydlige del af Sumatra har stort set ikke flyttet sig. 